\title{
A Community Based Cohort Study on Usefulness of Leishmanin Skin Test in Detection of Immunoreactivity Against Leishmania donovani Infection in an Endemic Area of Kala-Azar, Bihar, India
}

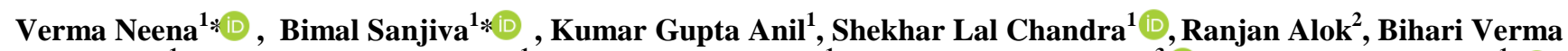 \\ Rakesh $^{1}$, pandey-Krishna Pandey ${ }^{1}$, Nand Rabidas Vidya ${ }^{1}$, Kar Shantanu Kumar ${ }^{3}$ (D), Das P- Pradeep Das ${ }^{1}$ \\ ${ }^{1}$ Rajendra Memorial Research Institute of Medical Sciences, (Indian Council of Medical Research), Agamkuan, Patna - 800007, \\ Bihar, India. ${ }^{2}$ All India Institute of Medical Sciences,Phulwarisarif, Patna, Bihar, India. ${ }^{3}$ Regional Medical Research Centre \\ (Indian Council of Medical Research), Chandrashekharpur, Bhubaneswar, Orissa, India
}

\begin{tabular}{l} 
A R T I C L E I N F O \\
\hline Original Article \\
VacRes, 2019 \\
Vol. 6, No.2, 42- 46 \\
Received: January 21, 2020 \\
Accepted: May 31, 2020 \\
Pasteur Institute of Iran \\
*Corresponding Author: \\
I. Neena Verma. Former Scientist 'F' \& \\
Head, Division of Pathology, Rajendra \\
Memorial Research Institute of Medical \\
Sciences, Indian Council of Medical \\
Research, Agamkuan, Patna-800 007. India. \\
Email: neenaverma.icmr@gmail.com, \\
verma_neena@yahoo.com \\
Tel/Fax: +916122634379 \\
II. Sanjiva Bimal, Scientist 'F' \& Head, \\
Division of Immunology Rajendra \\
Memorial Research Institute of Medical \\
Sciences, Indian Council of Medical \\
Research, Agamkuan, Patna-800 007. India. \\
Email: drsanjiva24@yahoo.com \\
Tel/Fax: +916122634379
\end{tabular}

KEYWORDS: Leishmanin Skin Test (LST), Visceral Leishmaniasis (VL), CellMediated Immunity (CMI), Kala-Azar (KA), Direct Agglutination Test (DAT).

\section{A B S T R A C T}

Introduction: Control efforts of visceral leishmaniasis (VL) are hindered due to inappropriate early case detection of Leishmania infection with varying degree of susceptibility to develop the disease. Methods: We assessed the current infection status using Leishmanin skin test (LST) and direct agglutination test (DAT) in a cohort population (206 randomly selected individuals) in a VL endemic area of Bihar, India. Results: Cellular immunity was revealed in $18.4 \%$ and antibody response in $18.9 \%$ of the population. The age-group of 20-29 years were most vulnerable. DAT titer was inversely proportional to duration of past history of VL. The houses having present or past history of kala-azar in family were observed with high Leishmanin and DAT positivity, indicating relevance of household contacts in the disease transmission. Conclusion: The reactivity of both LST and DAT tests may help in identifying the possible groups with varying degree of susceptibility and risk of infection or having prior exposure to the leishmania infection with or without development of the disease.

\section{Citation:}

Verma N, Bimal S, Gupta Anil K, Lal C, Ranjan A, Verma R, et al . A Community Based Cohort Study on Usefulness of Leishmanin Skin Test in Detection of Immunoreactivity Against Leishmania donovani Infection in an Endemic Area of Kala-Azar, Bihar, India. vacres. 2019; 6 (2) :42-46. DOI: 10.29252/vacres.6.2.42

\section{INTRODUCTION}

Leishmania donovani infection incites varieties of immune responses in human which is reflected through either manifestation of active disease of kala-azar (KA)/post kala-azar dermal leishmaniasis (PKDL) in the host or no overt disease. There may be several population groups between these two extremes, showing different pattern of immuno-reactivity that need to be defined by the epidemiological studies. On the other hand, only few manifest clinical symptoms of KA in the endemic areas of high transmission, even with same degree of exposure to the infection. The existence of sub-clinical and asymptomatic infections in the host has also been reported [1].
This suggests that the endemic population reflects a heterogeneous group, consisting of sub-groups of individuals who are apparently healthy or infected with no sign or symptoms of clinical or sub-clinical stage or with overt clinical disease. Estimation of the infection status and its dynamics over time in an endemic population may help to understand the disease's epidemiology.

Leishmanin skin test (LST) in combination with determination of circulating antibodies are important tools in epidemiological, immunological and diagnostic studies of Visceral Leishmaniasis (VL) [2] in regions where it is a major 
health problem. Specific skin test reactivity has often been associated with immunity to the re-infection and skin test cross reactivity is usually paralleled by comparable cross immunity [3]. With currently available epidemiological tools, like LST that depicts the past infection and direct agglutination test (DAT) that indicates recent KA infection along with clinical evaluations, the endemic population could be segregated into sub-groups according to their infection status. In Bihar, India, $\mathrm{KA}$ is a major health problem, particularly in north districts, situated in planes of river Ganges where on average, 1500-2500 cases are reported annually. The study of LST and DAT in KA endemic population has not been reported from this state. A delayed type hypersensitivity (DTH) response, manifested as a positive skin test, is associated with the protection and might be a valuable tool for evaluating the vaccine trials. Estimates of a susceptible target population for intervention programs are essential requisites to plan the future control strategies. In the present study, LST and DAT with clinical examination were undertaken on a cohort population from an endemic village of KA in North Bihar, India with objectives to demonstrate the immunoreactivity and current infection status of the defined population, screened from the study area.

\section{MATERIALS and METHODS}

\section{Study Population}

An endemic village for KA, 'Sharma' from Vaishali district of Bihar, India, situated approximately $20 \mathrm{~km}$ from the river Ganges, known to be endemic for KA with a de jure population of 719 , was selected for the study. As per the records available from local health center, the studied village was known to be endemic for KA since a decade or so with cases reported perennially. Each household was numbered, population enumerated and data on identification particulars and other important epidemiological information like age, sex, housing pattern, migration history, socio-economic factors, present and past history of KA were obtained. Out of 139 total households, 35 houses were selected randomly and all 206 individuals residing there were included in the study. The study \& sampling period was during year 1998-2000. All study subjects were examined clinically with detail history related to $\mathrm{KA}$ and BCG vaccination. Clinical signs like temperature, pallor, hepatosplenomegaly, lymph node enlargement and other related features were recorded in the standard Performa. In KA suspected cases, bone marrow/splenic aspiration was done for microscopic detection of the Leishmania parasite. The study population screened as above was identified into various subgroups, namely confirmed KA cases, cured KA cases with period ranging from $0-5,6-10$ and more than 10 years and noncontacts.

\section{Leishmanin Skin Test (LST)}

Leishmanin antigen (L. major, Pasteur Institute of Iran, Lot-III) provided by Tropical Disease Research, World Health Organization (WHO), Geneva, Switzerland and was used for LST. It was a suspension of promastigotes of L. major $(107 / \mathrm{ml})$ in $0.5 \%$ phenol saline. Leishmanin was injected intradermally in a dose of $0.1 \mathrm{ml}$ on the volar aspect of the left forearm. On the right forearm, intradermal injection of $0.1 \mathrm{ml}$ of $0.5 \%$ phenol saline was injected and served as a control. Subjects cured of KA between 6 to 12 months period after the treatment and attending follow-up clinic at RMRI OPD served as positive control.
Skin reactions in the forms of erythema and induration were assessed between 48-72 $\mathrm{h}$ by ballpoint pen method [4], the recommended technique by WHO. Briefly, a line was drawn with a ballpoint pen about $1-2 \mathrm{~cm}$ from margin of the skin induration towards its center. On sensation of resistance to further movement, the pen was lifted from the skin. The procedure was repeated on the opposite side of the skin reaction. This procedure was further repeated at right angles, to generate a two dimensional measurements of the induration. The diameter of the induration was established by taking the mean of the lengths measured with a ruler in $\mathrm{mm}$, between the two pairs of opposite lines. A reaction with erythema and induration of $4 \mathrm{~mm}$ or above was considered as positive. An erythematous response alone or skin reactions less than $4 \mathrm{~mm}$ were recorded as negative [5].

\section{Direct Agglutination Test (DAT)}

Peripheral blood was collected by finger prick on Whatman filter paper No 4 from all study subjects and were then air-dried and stored in polythene bags at $-20^{\circ} \mathrm{C}$. For elution, a small disc of dried blood spot was extracted overnight at $4^{\circ} \mathrm{C}$ in $2800 \mu \mathrm{l}$ of $0.15 \mathrm{M}$ saline (1: 400 dilutions of the sera). The antigen used was trypsinized $(0.4 \%)$, formalin fixed $(2 \%)$ and $0.1 \%$ Coomassie brilliant blue stained promastigotes $(50 \mathrm{x}$ 106) of L. donovani [6]. Fifty microlitres $(\mu \mathrm{l})$ suspension was added to serial sera dilution in 96 well $\mathrm{V}$-shaped microtiter plate [7]. The filter paper blood were serially diluted to $1: 1600$, $1: 3200,1: 6400$ and $1: 12800$ in $0.15 \mathrm{M} \mathrm{NaCl}$ to which $0.1 \mathrm{M} \mathrm{2-}$ mercaptoethanol and $0.2 \%$ gelatin (Difco, USA) was added. A dilution of 1:3200 was taken as a cut-off titer.

\section{Statistical Analysis}

The Yates-corrected Chi-square test was used for comparing proportion of two groups and student's t-test was used for comparing means. The Mantel-Hanszel method was used for calculating odd-ratio (OR) for two groups. Epi-info version- 6 has been used for statistical analysis.

\section{Ethical Issues}

Ethical approval for the study was obtained from Institutional ethical committee and was approved by the Scientific Advisory Committee, Rajendra Memorial Research Institute of Medical Sciences, Indian Council of Medical Research, India. The study subjects were well informed and their consents were obtained prior to perform the tests.

\section{RESULTS}

All 206 sampled population that comprised the $32 \%$ of total population of the village, were screened for both LST and DAT with clinical evaluations. The village population enumerated had significant proportion of children, whose age ranged between 1 to 12 years. The age and sex structure of the village population was comparable to that of the studied sampled population $(\mathrm{p}>0.05)$. Population migration from nearby districts was observed in $9 \%$ of the total population. The village was agriculture based where most of the villagers were either farmers or unskilled laborers. Illiteracy (53\%) was high amongst the population. Most of the houses were kutchha that could favor sandfly breeding.

Out of 206 subjects, 38 (18\%) were found LST positive. Significant difference in LST positivity was observed among the various age-groups $\left(X^{2}=11.59\right.$ at 4 d.f., $\left.p=0.02\right)$. The age- 
group in the range of 20-29 had shown highest proportion of LST positivity as compared to other age-groups (Table 1). However, no significant gender difference of LST positivity was observed $\left(\mathrm{X}^{2}=0.01, \mathrm{p}=0.90\right)$. Household contacts (i.e. individuals residing in houses where at least one member has or had KA), had significantly higher frequency of LST positivity as compared to those of non-contacts $\left(\mathrm{X}^{2}=8.74\right.$ at 1 d.f., $\mathrm{p}=$ 0.003).

Individuals with past history of KA revealed higher frequency of LST positivity $\left(\mathrm{X}^{2}=27.62\right.$ at 1 d.f, $\left.\mathrm{p}=0.00001\right)$. Proportion of LST positivity amongst individuals having past VL history for different durations was compared. This was higher in the groups experiencing VL in last 5 years $(68 \%)$ than those with a history beyond 5 years $(30 \%)$.

No significant difference was observed in proportion of sero-positivity among the various age-groups $\left(X^{2}=6.71\right.$ at 4 d.f., $\mathrm{p}=0.15$ ), as shown in Table 2 . Also, sex did not show any significant difference of sero-positivity $\left(X^{2}=0.02\right.$ at 1 d.f., $p=$ $0.88, \mathrm{OR}=0.99, \mathrm{CI}=0.46-12.12$ ). Proportion of sero-positives was compared between contacts and non-contacts. Significant proportion of family contacts were found to be DAT positive as compared to non-contacts $\left(\mathrm{X}^{2}=7.03\right.$ at 1 d.f., $\mathrm{p}=0.008, \mathrm{OR}=$ 6.62 , C.I. $=1.47-41.45)$. The highest prevalence of Leishmanin and sero-positive individuals was found in the agegroup 20-29 (Table 1, 2).

Table 1. Age-wise distribution of LST.

\begin{tabular}{|c|c|c|}
\hline Age Group & $\begin{array}{c}\text { Number of subjects } \\
\text { tested }\end{array}$ & $\begin{array}{c}\text { Number } \\
\text { positive (\%) }\end{array}$ \\
\hline $0-9$ & 67 & $12(17.9)$ \\
\hline $10-19$ & 46 & $6(13.0)$ \\
\hline $20-29$ & 13 & $6(46.1)$ \\
\hline $30-39$ & 32 & $9(28.1)$ \\
\hline$\geq 40$ & 48 & $5(10.4)$ \\
\hline Total & 206 & $38(18.4)$ \\
\hline
\end{tabular}

*Chi-square $=11.59$ at 4 d.f., $\mathrm{p}=0.0206$

Table 2. Age-wise distribution of DAT.

\begin{tabular}{|c|c|c|}
\hline Age Group & $\begin{array}{c}\text { Number of subjects } \\
\text { tested }\end{array}$ & $\begin{array}{c}\text { Number } \\
\text { positive (\%) }\end{array}$ \\
\hline $0-9$ & 67 & $14(20.9)$ \\
\hline $10-19$ & 46 & $5(10.8)$ \\
\hline $20-29$ & 13 & $5(38.4)$ \\
\hline $30-39$ & 32 & $8(25.0)$ \\
\hline$\geq 40$ & 48 & $7(14.6)$ \\
\hline Total & 206 & $39(18.9)$ \\
\hline
\end{tabular}

\#Chi-square $=6.71$ at 4 d.f., $p=0.15$

Fifteen of 32 subjects, with past history of KA, were found seropositive. Sero-positivity was found to be significantly associated with past history of KA of the subjects screened $(\chi 2=17.18$ at 1 d.f., $\quad \mathrm{p}=0.00003, \quad \mathrm{OR}=5.51, \quad \mathrm{CI}=2.26-13.52) ; \quad$ however, the proportion of sero-positivity was significantly less amongst subjects having past history of KA beyond 10 years than those of less than 10 years. Two active KA cases observed during the study had high titer of DAT (1:6400). Thirteen out of 21 (62\%) persons who had history of KA, 2 to 10 years back were DAT positive whereas only 2 out of 11 persons (18\%), who had KA more than 10 years back, were DAT positive.

Comparison of Leishmanin Reactions and Antibody Titer Among the Study Groups
Out of 206 individuals of both sexes screened by DAT and LST, 39 (18.9\%) were positive by DAT and 38 (18.4\%) were positive by LST. Only 2 of the 39 DAT positive subjects were active cases of KA who did not show reactivity against Leishmanin test. Cross-reactivity of LST and DAT revealed that out of 206 individuals, $12(5.8 \%)$ were positive by both tests, $26(12.6 \%)$ were LST positive and DAT negative, $27(13.1 \%)$ were DAT positive and LST negative and $141(68.4 \%$ ) were negative by both (Table 3 ).

Table 3: Cross-reactivity of LST and DAT.

\begin{tabular}{|c|c|c|c|}
\hline $\begin{array}{c}\text { DAT } \\
\text { LST }\end{array}$ & $\begin{array}{c}\text { Number } \\
\text { positive (\%) }\end{array}$ & $\begin{array}{c}\text { Number } \\
\text { negative (\%) }\end{array}$ & Total (\%) \\
\hline Positive & $12(5.8 \%)$ & $26(12.6)$ & $38(18.4)$ \\
\hline Negative & $27(13.1 \%)$ & $141(68.4)$ & $168(81.5)$ \\
\hline Total & $39(18.9)$ & $167(81.0)$ & 206 \\
\hline
\end{tabular}

\section{DISCUSSION}

While DAT positive status is thought to be an indicator of recent infection, Leishmanin or LST positivity may be associated with past history of KA or acquisition of the infection followed by immunity. Since both these indicators can change over time, it is possible to get subsets of the endemic population in phase of transition. The LST with determination of circulating antibodies is an important tool in epidemiological, immunological and diagnostic studies of VL in regions where it is a major health problem [2]. Based on observation of excellent concordance between these two tools used, it was suggested that these tests can be able to detect potential cases of reactivated VL [8]. While LST has been recommended to determine status of the cell-mediated immunity (CMI) and an indicator of the past infection [9], DAT has been evaluated for diagnostic purposes in VL $[7,10]$. Besides, LST has been used to detect asymptomatic cases with the possibility of their contact with leishmania parasite and to assess transmission of the parasites in the endemic foci [11, 12]. The present study indicates high prevalence of LST positivity (18\%) amongst the selected endemic population. Similar reports were also documented from Somalia [13]. However, higher LST positive rates were obtained amongst population from Somalia (26\%) [14] and France (30\%) [8]. The percentage of positive results in Leishmanin test was higher in areas where recent cases of human VL had occurred [11]. The village studied here had reported cases of VL for the last several years, thus indicating an epidemiologically stable situation with intense continued transmission of the infection. The frequency of positive reaction to leishmanin test increased with age (highest being observed in 20-29 years of age group), thereafter, the rate declined. This was in agreement with other reports [14]. Age distribution of LST positivity suggests time limited CMI in VL. It has been shown that a protective immunity in VL is cell- mediated [15]. It is presumed that decreased number of LST positives in older individuals is indicative of increased susceptibility to re-infection [16]. However, when age of reporting VL is observed in this endemic population, the bulk comes from children and young adults; although, all age groups are affected. A report from Sudan also indicates that only $20 \%$ of VL patients belong to age of 35 years or older [17]. Whether LST positive status is an indicator of protection from rechallenge of the infection has not been shown in human. Two 
patients of the study area presenting with VL showed no reactivity to Leishmanin antigen which was in agreement with observations made earlier $[9,14,16,18,19,20]$.

In the present study, $47 \%$ of the individuals with past history of KA did not show reactivity to Leishmanin. Earlier reports suggest that even after lapse of 12 months period following cure from VL, nearly $20 \%$ of such individuals did not show reactivity to Leishmanin test $[19,20]$. Further, through the retrospective analysis it was evident that longer the duration of past history of VL, lesser was the frequency of LST positivity. It has been suggested that acquisition of LST positive status following cure from VL is not permanent $[2,21]$. The finding that $47 \%$ LST positive individuals with no past history of KA, can be ascribed to cases that have undergone self healing or passed through subclinical infection in the past. Report from Brazil has indicated that the ratio of VL disease to infection was 1:18.5 and $80 \%$ of those sero-positives did not show any overt symptoms or sign or even mild illness for a followed-up 15-month-period and eventually resolved spontaneously [22].

Both humoral and CMI responses in mild, asymptomatic and sub-clinical infections are less known. Only 2 of 39 sero-positives individuals in our present study complained of fever and hepatosplenomegaly. We therefore suppose that the majority of these DAT positive individuals might have been infected with Leishmania, resulting in mild or sub-clinical infections without any symptom of KA. It has been observed that a few years after recovery from VL, anti-bodies titers have significantly decreased to low levels [14, 23, 24]. It has also been shown that DTH reactions can remain positive for many years after the infection [11, 25]. Our observations also correspond to the same.

The basis of percentage prevalence of total antibody positivity cannot be taken as the reflection of complete VL spectrum on account of its non-discriminating nature between active, subclinical, early and cured cases of KA. Raised CMI status was observed in some cases with a little high antibody titer which may be due to sub-clinical infection. Even due to antigenic cross reactivity, sera from individuals with other infections along with $\mathrm{KA}$ in an endemic area may react with L. donovani antigen to give inaccurate information on the prevalence. In the present study, all the 39 DAT positive cases could not be classified as true cases since many were successfully treated with reduced hepatosplenomegaly and normal blood counts. Keeping in view of such limitations, we studied Leishmanin status of the area to find out if it could support antibodies titer in defining the prevalence of the infection in an endemic area.

The analyses of 39 DAT positive cases reflected that 27 of them were associated with the absence of cellular immunity due to negative intradermal skin test to L. donovani antigen. This study is in agreement to the findings that reactivity of an individual in the form of DTH to leishmanial antigen are not significant in KA [9]. Taking this feature into account, it is logical to carry out antibodies assessment through DAT with additional assessment of CMI profile to define the prevalence of VL in an endemic area. LST which is simple and field-based can be a useful cellular component to be included in an epidemiological study.

Among the total of 38 LST positive and 39 DAT positive individuals, $12(5.8 \%)$ were positive by both tests. This may be due to reactivation of the Leishmania infection in a previously immune individual or due to presence of antibodies in VL cases just after cure from the disease. It has been shown in mouse model systems that the outcome of many infections including leishmaniasis, is regulated by the balance of functionally different CD4+ $\mathrm{T}$ helper cells, which can be separated into Th1 and Th2, depending on the profile of cytokines they produce following an antigenic simulation [26]. Our findings call for further investigations on the interrelationship between humoral and cellular immunity of VL.

Out of 206 individuals screened by both tests, 26 (12.6\%) were LST positive and DAT negative, indicating a probably immune population in the community; also 27 (13\%) were DAT positive and LST negative showing the currently infected population. The rest $141(68 \%)$ were both DAT and LST negative, probably indicating the susceptible population in the community. This type of stratification, on the basis of screening by two tests in the community, may prove to be very helpful in planning the control strategy of the disease.

The overall prevalence of infection as determined by $\mathrm{L}$. donovani antibody titer was 189 per 1000, suggesting a close monitoring of this area for future epidemic stage. Most of those with positive serology in the survey were young adults (20-29) and had no sign and symptoms of VL. The underlying problem with serological surveys is that anti-leishmania antibodies can persist in the sera long after the clinical cure [20, 23]. Unless there is a prospective follow-up of the serological positives as well as negatives $[10,22]$, it is hard to predict the number who will develop the disease. In conclusion, the stratification done on the basis of screening VL by simultaneous application of LST and DAT in the endemic community may provide valuable information in planning the control strategies of KA.

\section{ACKNOWLEDGMENT}

The authors are grateful to Dr. F. Modabber (Tropical Disease Research, WHO, Geneva, Switzerland) for providing Leishmanin antigen. We wish our sincere thanks to technical staffs for active participation and co-operation of this study. Further, we declare that no special financial assistance was provided by any funding agency for conducting this study.

\section{CONFLICT OF INTEREST}

The authors declare that they have no conflict of interest.

\section{REFERENCES}

1. Saran R, Gupta A K, Sharma M C. Evidence of Leishmania donovani infection in household members residing with visceral leishmaniasis patients. J Commun Dis. 1992 Dec; 24(4):242-4.

2. Manson-Bahr P E, Heisch R B, Garnham P C. Studies in Leishmaniasis in East Africa. IV. The Montenegro Test in Kala-Azar in Kenya. Trans R Soc Trop Med Hyg. 1959 Sep; 53:380-3. doi: 10.1016/00359203(59)90038-0.

3. Manuel $\mathrm{J}$, and Behin $\mathrm{R}$, Immunological cross-reactivity between leishmania species and the problem of vaccination, Immunology of parasitic diseases, 2nd edition, Cohen,s. \& Warren, K.S. (editor) London : Blackwell Scientific Publication pp. 299-355, 1982.

4. Sokal JE. Measurement of delayed skin-test responses. N Engl J Med 1975; vol. 293:501-502 DOI: 10.1056/NEJM197509042931013

5. Saran R, Gupta AK, Sharma MC. Leishmanin skin test in clinical and subclinical kala-azar cases. J Commun Dis. 1991 Jun; 23(2): 135-7.

6. Harith A E, Kolk A H, Kager P A, Leeuwenburg J, Muigai R, Kiugu S, Laarman J J. A simple and economical direct agglutination test for serodiagnosis and sero-epidemiological studies of visceral leishmaniasis. 
Trans R Soc Trop Med Hyg. 1986; 80(4): 583-6. doi: 10.1016/00359203(86)90149-5.

7. El Harith A, Kolk A H, Leeuwenburg J, Muigai R, Huigen E, Jelsma T, Kager P A. Improvement of a direct agglutination test for field studies of visceral leishmaniasis. Journal of clinical microbiology. 1988 Jul 1; 26(7): 1321-5. DOI: 10.1128/JCM.26.7.1321-1325.1988.

8. Marty P, Fichoux Le Y, Giordana D, Brugnetti A. Leishmanin reaction in the human population of a highly endemic focus of canine leishmaniasis in Alpes-Maritimes, France. Trans R Soc Trop Med Hyg. May-Jun 1992; 86(3): 249-50. doi: 10.1016/0035-9203(92)90295-n.

9. Ho M, Koech D K, Iha D W, Bryceson A D. Immunosuppression in Kenyan visceral leishmaniasis. Clinical and experimental immunology. 1983 Feb; 51(2): 207.

10. Evans T G, Teixeira M J, McAuliffe I T, Barros Vasconcelos I de A, Vasconcelos A W, Sousa A de Q, de Oliveira Lima J W, Pearson R D. Epidemiology of visceral leishmaniasis in northeast Brazil. J Infect Dis. 1992 Nov; 166(5): 1124-32. doi: 10.1093/infdis/166.5.1124.

11. Sánchez C A, Sánchez J M, Bernal I D V, Marín M C S, Louassini M, Maldonado J A, Márquez F M. Leishmaniasis eco-epidemiology in the Alpujarra region (Granada province, southern Spain). Int J Parasitol. 1996 Mar; 26(3):303-10. doi: 10.1016/0020-7519(95)00124-7.

12. Gramiccia M, Bettini S, Gradoni L, Ciarmoli P, Verrilli ML, Loddo S, Cicalo C. Leishmaniasis in Sardinia. 5. Leishmanin reaction in the human population of a focus of low endemicity of canine leishmaniasis. Transactions of the Royal Society of Tropical Medicine and Hygiene. 1990 May; 84(3):371-374, doi.org/10.1016/0035-9203(90)90322-6.

13. Cahill K M, Mazzoni P L, Aden H. A leishmanin survey in Giohar, Somalia. Transactions of the Royal Society of Tropical Medicine and Hygiene. 1967; 61(3):340-2. DOI : 10.1016/0035-9203(67)90006-5

14. Shiddo SA, Akuffo HO, Mohamed AA, Huldt G, Nilsson LA, Ouchterlony Ö, Thorstensson R. Visceral leishmaniasis in Somalia: prevalence of leishmanin-positive and seropositive inhabitants in an endemic area. Transactions of the Royal Society of Tropical Medicine and Hygiene. 1995 Jan 1;89(1):21-24, DOI: 10.1016/0035-9203(95)90640-1

15. Reed SG, Scott P. T-cell and cytokine responses in leishmaniasis. Current opinion in immunology. 1993 Aug 1;5(4):524-31. DOI: 10.1016/0952-7915(93)90033-o
16. P. E. C. Manson-Bahr, "Immunity in Kala-azar", Transaction of the Royal Society of Tropical Medicine and Hygiene. 1961 Nov. vol. 55, pp. 550-555. doi.org/10.1016/0035-9203(61)90078-5

17. Beer De P, Harith EL A, Grootheest Van M, Winkler A. Outbreak of kala-azar in the Sudan. Outbreak of kala-azar in the Sudan. Lancet. 1990 Jan 27;335 (8683): 224. doi: 10.1016/0140-6736(90)90313-t.

18. Haldar J P, Ghose S, Saha K C, Ghose A C. Cell-mediated immune response in Indian kala-azar and post-kala-azar dermal leishmaniasis. Infect Immun. 1983 Nov; 42(2): 702-7.

19. Neogy A B, Nandy A, Dastidar B G, Chowdhury A B. Leishmanin test in Indian kala-azar. Trans R Soc Trop Med Hyg 1986;80 (3): 454-5. doi:10.1016/0035-9203(86)90341-x.

20. Zijlstra E E, El-Hassan A M. Leishmanin and tuberculin sensitivity in leishmaniasis in the Sudan, with special reference to kala-azar. Trans R Soc Trop Med Hyg. Jul-Aug 1993; 87(4): 425-7. doi: 10.1016/00359203(93)90024-k.

21. Van Peenen PF, Dietlein DR. Leishmaniasis in the Sudan Republic. 14 Leishmanin skin testing in Upper Nile Province. J Trop Med Hyg 1963 Jul;66:171-4.

22. Badaro R, Jones T C, Carvalho E M, Sampaio D, Reed S G, Barral A, Teixeira R, Johnson Jr W D. New perspectives on a subclinical form of visceral leishmaniasis. The Journal of infectious diseases.1986 Dec 1;154(6):1003-1011.http://doi.org/10.1093/infdis/154.6.1003.

23. Hailu A. Pre-and post-treatment antibody levels in visceral leishmaniasis. Trans R Soc Trop Med Hyg Sep-Oct 1990; 84(5): 673-5. doi: 10.1016/0035-9203(90)90141-z.

24. Singla N, Singh G S, Sundar S, Vinayak V K. Evaluation of the direct agglutination test as an immunodiagnostic tool for kala-azar in India. Trans R Soc Trop Med Hyg. May-Jun 1993; 87(3): 276-8. doi: 10.1016/00359203(93)90125-a.

25. Leeuwenburg J, Bryceson A D, Mbugua G G, Siongok T K. The use of the leishmanin skin-test to define transmission of leishmaniasis in Baringo district, Kenya. East Afr Med J. 1983 Feb; 60(2): 81-4.

26. Mosmann T R, Cherwinski H, Bond M W, Giedlin M A, Coffman R L. Two types of murine helper $\mathrm{T}$ cell clone. I. Definition according to profiles of lymphokine activities and secreted proteins. J Immunol. $1986 \mathrm{Apr}$ $1 ; 136(7): 2348-57$. 